\title{
A comparison of IL-17 and IL-34 concentrations in the cerebrospinal fluid of patients with acute inflammatory demyelinating neuropathy and chronic inflammatory demyelinating polyneuropathy
}

\section{SUMMARY}

OBJECTIVE: The role of interleukins, such as IL-17 and IL-34, in the pathogenesis of autoimmune diseases has been established in the literature. In the current study, we aimed to identify the concentrations of IL-17 (IL-17A, IL-17F) and IL-34 in the cerebrospinal fluid (CSF) of patients with chronic inflammatory demyelinating polyneuropathy (CIDP) and acute inflammatory demyelinating neuropathy (AIDN). METHODS: We included in this study 8 patients with CIDP (none of them receiving immunomodulatory or immunosuppressant therapy), 7 patients with Guillain-Barre syndrome (GBS, AIDN), and 7 control subjects. The CIDP and AIDN diagnoses were made by clinical evaluation and electrophysiological investigations according to international criteria. CSF samples were obtained appropriately, and the levels of IL-17A, IL-17F, and IL-34 were measured by ELISA kits.

RESULTS: The concentrations of IL-17A, IL-17F, and IL-34 were higher in those with CIDP and AIDN compared to the controls ( $p=0.005$, $p=0.01$, and $p=0.001$, respectively). While IL-34 levels were significantly higher in AIDN patients than in CIDP patients ( $p=0.04)$, there were no significant differences between the AIDN and CIDP groups with regard to the levels of IL-17A and IL-17F ( $p=0.4$ and $p=0.2$, respectively)

CONCLUSION: Our results indicate that IL-17A, IL-17F, and IL-34 levels may have a role in CIDP and AIDN. Furthermore, the difference in the IL-34 levels of patients with AIDN and CIDP may indicate an important difference between the pathogenesis of these two sets of the disease.

KEYWORDS: Gullian-Barre Syndrome. Cytokines. Interleucinas. Interleukin-17. Interleukin-34.

\section{INTRODUCTION}

GBS is a post-infectious autoimmune disease that causes symmetrical motor weakness and sensorial loss. It is the second leading cause of acute and subacute generalized paralysis. Electrophysiologically speaking, there are three subtypes of this syndrome: acute motor axonal neuropathy (AMAN), which has the worst prognosis; acute motor-sensory axonal neuropathy (AMSAN); and acute inflammatory demyelinating neuropathy (AIDN), which is mostly known as the classical form of GBS 1 . The pathophysiology of AIDN is characterized by the segmental demyelination of the proximal myelinated neurons in roots and 
plexuses. Despite the fact that the underlying immunological mechanism is yet to be fully understood, current evidence shows that both humoral and cellular pathways are involved in the pathogenesis. There is some evidence in the literature that $\mathrm{T}$ cells play a crucial role in the AIDN pathophysiology. For instance, $\mathrm{T}$ lymphocytes and macrophages have been shown to infiltrate peripheral nerves and directly attack myelin proteins PO, P2, and PMP22 ${ }^{2}$. Furthermore, in addition to the increase in cerebrospinal flood (CSF) concentrations of T-cell-associated cytokines (such as IL-17, IFN- $\gamma$, and IL-22), the blood levels of T helper (Th) 1 and Th-17 have been found to be increased in AIDN ${ }^{3,4}$. Recent studies have also shown that IL-14, IL-12, IL-23, IL-27, IL-35 also partake in the immune response ${ }^{5}$. However, the role of other cytokines (such as IL34) in the pathogenesis of AIDN is unknown.

Chronic inflammatory demyelinating polyneuropathy (CIDP) is another similar immune-mediated autoimmune disease. Its clinical findings are similar to those of AIDN; however, the disease course in this condition demonstrates a chronic relapsing-remitting characteristic ${ }^{6}$. The pathophysiology of CIDP is also unclear. In many studies, the presence of both humoral and cell-mediated immune responses have been reported ${ }^{7,8}$. Presumably, as is the case in AIDN, the main target for these immune cells is the myelin. Matsumuro et al. ${ }^{9}$ and Rizutta et al. ${ }^{10}$ found that $\mathrm{CD} 4{ }^{+}$ and $\mathrm{CD}^{+} \mathrm{T}$ cells activate macrophages in concert, which then infiltrate the sural nerve. They concluded that $\mathrm{T}$ cells, therefore interleukins, may have a critical role in CIDP development ${ }^{9,10}$.

IL-17 is a pro-inflammatory cytokine that consists of 150 amino acids. It has 6 subtypes, all of which share sequence homology but are distinct with regard to tissue expression. They are produced by Th17 and their overexpression causes several autoimmune diseases including experimental autoimmune encephalomyelitis (EAE), a murine model of multiple sclerosis (MS), and rheumatoid arthritis". In recent studies, there have been conflicting results about the association between IL-17 and CIDP, while most studies have reported that IL-17 may have an important role in CIDP ${ }^{12-14}$, some researchers did not find any association ${ }^{15}$. On the other hand, the role of IL-17 in AIDN is relatively clearer, as most of the studies have determined a critical role for IL-17 in AIDN pathophysiology ${ }^{16,17}$.

IL-34 is a hematopoietic cytokine that plays a key role in the survival, proliferation, and differentiation of myeloid stem cells ${ }^{18}$. Particularly, IL-34 is suggested to have an important role in the preservation of central nervous system homeostasis by its action(s) on different cell types including neurons, microglia, and endothelial cells. In the latest studies, there is growing evidence that IL-34 contributes to the pathogenesis of various conditions including autoimmune disorders ${ }^{19}$.

In this study, we aimed to identify the concentrations of IL-17 (IL-17A, IL-17F) and IL-34 in CSF samples from patients with CIDP and AIDN.

\section{METHODS}

This study was conducted in the Abant İzzet Baysal University Medical Faculty, Department of Neurology, from 2013 to 2017. The study and its conduct were approved by the local ethics committee (protocol number; 2018/203) and informed consent forms were obtained from all participants. The Helsinki Declaration was followed during the study period and the writing of the article.

We included in this study a total of 8 CIDP, 7 GBS (AIDN) patients, and 7 control subjects. CIDP patients met the Possible, Probable, or Definite criteria for Typical or Atypical CIDP of the EFNS/PNS Joint Task Force $^{20}$. None of the patients with CIDP were using any medication for CIDP such as immunomodulatory or immunosuppressant drugs at the time of CSF withdrawal. GBS was diagnosed according to the international criteria for GBS or its variants, and AIDN diagnosis was defined and confirmed via electrophysiological investigations ${ }^{21}$. Both CIDP and AIDN patients did not have any accompanying diseases which could confound any measurements (such as other autoimmune diseases, Systemic Lupus Erythematosus, Sjögren syndrome, and diabetes mellitus) performed in this study. The patients constituting the control group were patients with normal pressure hydrocephalus and no additional pathology was detected after CSF results. All participants' sociodemographic and clinical data were recorded.

Electrophysiological examinations were performed via EMG device in the same room with a temperature of $24-25^{\circ} \mathrm{C}$, by the same investigator for all patients. All patients underwent the tests in a quiet room, lying on the examination desk in the supine position. The control group was comprised of patients who did not have a history of neurological or psychiatric disease and had been suspected to have normal pressure hydrocephalus (NBH), but evaluations showed that 
they did not have NBH or any other neurological disease. All controls' detailed neurological examinations were completely normal. CSF samples were obtained via appropriate methods from all participants and samples were stored at $-80{ }^{\circ} \mathrm{C}$ until measurements were performed. In both groups, the levels of IL-17A, IL-17F, and IL-34 levels ( $\mathrm{pg} / \mathrm{mL})$ were measured from the CSF samples via commercially available ELISA kits (Elabscience and Cloud-Clone, USA). The biochemical parameters of the CSF were measured.

\section{Statistical analysis}

Data were analyzed using SPSS IBM 20.0 (SPSS Inc., Chicago IL) statistics software. The distribution of quantitative variables was assessed using the Kolmogorov-Smirnov test and results were presented as median $\left(25^{\text {th }}\right.$ percentile- $75^{\text {th }}$ percentile). Categorical data were given as frequency and percent values (\%). The comparison of categorical variables was performed using chi-squared tests (Pearson and Fisher's exact tests), while quantitative variables were compared using the Kruskal Wallis tests for 3-group comparisons, while the Mann-Whitney U test was used for 2-group comparisons. The level of statistical significance was set at $\mathrm{p}<0.05$.

\section{RESULTS}

All three groups were similar in terms of age and gender $(\mathrm{p}=0.253$ and $\mathrm{p}=0.959$ respectively). The average age was 60.8 in the control group, 64.8 in the CIDP group, and 68.0 in the AIDN group. The gender distribution was $2 \mathrm{~F} / 5 \mathrm{M}$ in AIDN, $1 \mathrm{~F} / 7 \mathrm{M}$ in CIDP, and $2 \mathrm{~F} / 5 \mathrm{M}$ in subjects in the control group. All patients with AIDN were found to have a history of infection prior to the development of GBS.

There were significant differences between groups in terms of IL-17A, IL17F, and IL-34 concentrations; these interleukin levels were higher in those with CIDP and AIDN compared to controls $(\mathrm{p}=0.005, \mathrm{p}=0.01$, and $p=0.001$, respectively). While IL-34 levels were significantly higher in the AIDN group than in the CIDP group ( $\mathrm{p}=0.04)$, there were no significant differences between the AIDN and CIDP groups regarding IL-17A and Il $-17 \mathrm{~F}$ ( $\mathrm{p}=0.4$ and $\mathrm{p}=0.2$ respectively). $\mathrm{CSF}$ protein and albumin levels were significantly higher in CIDP and AIDN groups compared to controls ( $p=0.023$ ), but there were no significant differences between the CIDP and AIDN groups $(p=0.23)$. Other biochemical CSF findings (glucose, $\mathrm{Na}, \mathrm{Cl}, \mathrm{LDH}$ ) were similar in all three groups (Table 1).

\section{DISCUSSION}

In the current study, the CSF concentrations of IL-17A, IL-17F, and IL-34 in patients with AIDN and CIDP were found to be significantly higher than in controls, and there were no differences between the CSF findings of the AIDN and CIDP groups regarding IL-17A and IL-17F levels. Apart from these results, the most interesting finding of this study can be seen as the higher levels of IL-34 in patients with AIDN compared to those with CIDP ${ }^{21}$.

Although it may be considered that there is an ongoing debate about the function(s) of IL-34, the majority of recent studies have found that it takes part in the differentiation and survival of macrophages, monocytes, and dendritic cells in response

TABLE1. CEREBROSPINAL FLUID FINDING OF THREE GROUPS

\begin{tabular}{l|l|l|l|l} 
& AIDN $(n=7)$ & CIDP $(n=8)$ & Control $(n=7)$ & $p$ \\
\hline CSF IL-17A $(\mathrm{pg} / \mathrm{ml})$ & $48(37-96)$ & $35(35-51)$ & $6(6-8)$ & $p=0.005$ \\
\hline CSF IL-17F $(\mathrm{pg} / \mathrm{ml})$ & $21(9-89)$ & $8(2-14)$ & $2(2-3)$ & $\mathrm{p}=0.010$ \\
\hline CSF IL-34 $(\mathrm{pg} / \mathrm{ml})$ & $57(38-65)$ & $22(19-44)$ & $3(3-7)$ & $\mathrm{p}=0.001$ \\
\hline CSF protein $(\mathrm{mg} / \mathrm{dL})$ & $71(71-105)$ & $96(75-172)$ & $23(23-36)$ & $\mathrm{p}=0,027$ \\
\hline CSF Albumin $(\mathrm{mg} / \mathrm{dL})$ & $6.06(4.5-6.7)$ & $5.88(5-7)$ & $2.45(2.1-2.6)$ & $\mathrm{p}=0.013$ \\
\hline CSF Na $(\mathrm{mEq} / \mathrm{l})$ & $135(135-137)$ & $133(131-134)$ & $136(132-139)$ & $\mathrm{p}=0.578$ \\
\hline CSF Cl $(\mathrm{mEq} / \mathrm{l})$ & 2 & & & $\begin{array}{l}.8(2.8-3.2) \\
2.7(2.7-3) \\
\end{array}$ \\
& & & & $\begin{array}{l}2.6(2.6-3.2) \\
\mathrm{p}=0.760\end{array}$ \\
\hline CSF LDH $(\mathrm{mg} / \mathrm{dL})$ & $68(64-75)$ & $57(46-67)$ & $40(40-51)$ & $\mathrm{p}=0.662$ \\
\hline CSF Glucose $(\mathrm{mg} / \mathrm{dL})$ & $42(41-62)$ & $33(33-42)$ & $29(29-31)$ & $\mathrm{p}=0.428$ \\
\hline
\end{tabular}

AIDN: acute inflammatory demyelinating neuropathy; CIDP: chronic inflammatory demyelinating neuropathy; CSF: cerebrospinal flood; IL: interleukin; LDH: lactate dehydrogenase. Data were presented as median ( $25^{\text {th }}$ percentile- $75^{\text {th }}$ percentile) 
to inflammation ${ }^{22}$. In the nervous system, cytokines are primarily produced by the neurons and present important effects in the central nervous system(CNS); it has been shown to activate the p-CREB pathway by binding Colony Stimulating Factor 1 Receptors (CSF R1) and upregulates factors that are involved in maintaining protection against neurotoxins ${ }^{23}$. In 2011, Mizuno et al. ${ }^{24}$ found that IL-34 provides microglial proliferation and up-regulates Insulin-Degrading Enzyme (IDE) and Heme Oxygenase-1 (HO-1), which is suggested to be the mechanism by which it provides a neuroprotective effect against Oligomeric Amyloid- $\beta$ neurotoxicity. In 2012, a study by D. Ma et al. ${ }^{25}$ supported this theory.

When the literature was reviewed, we did not find any study evaluating IL-34 concentrations in neither CIDP nor AIDN. Due to the elevated IL-34 concentrations in the CSF of both CIDP and AIDN in our study, we believe that IL-34 may have an important role in the immune activation of patients with CIDP and AIDN. Furthermore, the difference between IL-34 levels in patients with AIDN and CIDP may suggest the presence of an important difference between these clinically and characteristically similar diseases. It is well known that some AIDN cases can evolve into CIDP with time (in other words some CIDP cases may present with AIDN); however, it is currently impossible to determine whether CIDP will occur. Thus, the levels of IL-34 or the causes/results of its increase may be utilized as a marker to differentiate between these diseases and also to estimate whether a case with AIDN can evolve into CIDP. However, we are aware that our results require confirmation, and further studies with prospective design and adequate follow-up of patients must be performed to determine whether IL-34 levels can be utilized in this manner. It is rather apparent that this theory requires in-depth studies and a higher number of patients who are followed-up for a significant period of time. However, only a few studies have been performed in this field while, to our knowledge, this is the first study exploring the levels of IL-34 in patients with AIDN and CIDP. In this regard, we think that our research adds some important knowledge to the literature.

Compared to the data on IL-34 function, the function and structure of IL-17 are much clearer. The main source of IL-17 is specialized T cells, which are called Th-17. IL-17 has 6 subtypes that are named consecutively from IL-17A to IL17-F. Among these subtypes, IL-17A and IL-17F are the two that have received the most interest. Functionally, both of these interleukins have proinflammatory roles, albeit different with regard to inflammation type and region ${ }^{26}$. In a study by Liang et al. ${ }^{17}$, Th-17 and IL-17 were reportedly found to be involved in AIDN pathogenesis, findings which were partly confirmed by Han et al. ${ }^{16}$, who provided some evidence about the possible contribution of IL-17 on GBS pathogenesis. In another study conducted by Shujuan Li et al. ${ }^{27}$, GBS patients were found to demonstrate a significant elevation of plasma IL-17 and Th-17 concentrations; furthermore, intravenous immunoglobulin (IVIG) therapy was found to downregulate Th17 and IL-17 levels. As expected, due to their similar pathogenesis, many other studies also reported a possible relationship between IL-17 and CIDP ${ }^{12}$. For instance, Horste et al. ${ }^{13}$ detected that high numbers of IL-17-producing cells were related to younger age and shorter disease duration in CIDP. Our results were consistent with the literature on this topic; however, due to the fact that CSF is a direct indicator of the physiological status of the nervous system, we evaluated IL-17A and IL-17F levels in the CSF our patients. Considering that none of the aforementioned studies evaluated CSF IL-17 levels in both patients with AIDN and CIDP, we believe our results contribute to the literature by showing the differences (or similarities) between the diseases in terms of IL-17 levels in CSF.

There are some certain limitations in this research, i.e., the limited number of subjects; however, gathering a significant number of patients without any confounding factors, conditions or diseases can be very difficult, especially in a single center. Secondly, we could not evaluate the disease onset CSF findings of CIDP patients due to ethical concerns and also the study design. Finally, due to financial and technical limitations, we were unable to determine the levels of other cytokines, such as TNF $\alpha$, which may have provided further data with regard to the inflammatory characteristics of patients.

\section{CONCLUSION}

To conclude, although we had a limited number of patients and limited resources, we believe we have addressed an important knowledge gap regarding the differences (or similarities) between patients with AIDN and CIDP in terms of IL-17A, IL-17F, and IL-34 concentrations in the CSF. Our results suggest a possible role for IL-34 in AIDN pathogenesis; however, much research is required to draw a conclusion on 
this matter. However, more detailed prospective studies with a higher number of patients are required to clarify the association between IL-17, IL-34 levels, and the CIDP and AIDN.

\section{Acknowledgment}

The authors would like to thank the patients and their families.

\section{Disclosure statement}

No potential conflict of interest was reported by the authors.

\section{Ethical approval}

All procedures performed in the study involving human participants were in accordance with the ethical standards of the institutional and national research committee and with the 1964 Helsinki declaration and its later amendments or comparable ethical standards. This article does not contain any studies with animals performed by any of the authors.

\section{Author's Contributions}

The contribution of the authors is equal in all matters.

\section{RESUMO}

OBJETIVO: O papel das interleucinas, como IL-17 e IL-34, na patogênese da doença auto-imune foi estabelecido na literatura. No presente estudo, objetivamos identificar as concentrações de IL-17 (IL-17A, IL-17F) e IL-34 no líquido cefalorraquidiano (LCR) de pacientes com polineuropatia desmielinizante inflamatória crônica (CIDP) e neuropatia desmielinizante inflamatória aguda (AIDN).

MÉTODOS: incluímos neste estudo 8 pacientes com CIDP (nenhum deles recebendo terapia imunomoduladora ou imunossupressora), 7 pacientes com síndrome de Guillain-Barre (GBS, AIDN) e 7 indivíduos controle. Os diagnósticos CIDP e AIDN foram feitos por avaliação clínica e investigações eletrofisiológicas de acordo com critérios internacionais. As amostras de LCR foram obtidas adequadamente e os niveis de IL-17A, IL-17F e IL-34 foram medidos através de kits ELISA.

RESULTADOS: As concentrações de IL-17A, IL-17F e IL-34 foram maiores naqueles com CIDP e AIDN em comparação aos controles ( $p=$ $0,005, p=0,01$ ep = 0,001, respectivamente). Enquanto os níveis de IL-34 foram significativamente mais altos nos pacientes com AIDN do que nos pacientes com CIDP $(p=0,04)$, não houve diferenças significativas entre os grupos com AIDN e CIDP em relação aos níveis de IL-17A e IL-17F ( $p=0,4$ ep =0,2, respectivamente)

CONCLUSÃo: Nossos resultados indicam que os níveis de IL-17A, IL-17F e IL-34 podem ter um papel no CIDP e no AIDN. Além disso, a diferença nos níveis de IL-34 de pacientes com AIDN e CIDP pode indicar uma diferença importante entre a patogênese desses dois conjuntos de doenças.

PALAVRAS-CHAVE: Síndrome de Guillain-Barré. Citocinas. Interleukins. Interleucina-17. Interleucina-34.

\section{REFERENCES}

1. Yuki N, Hartung HP. Guillain-Barré syndrome. N Engl | Med. 2012;366(24):2294-304.

2. Csurhes PA, Sullivan AA, Green K, Pender MP, McCombe PA. T cell reactivity to P0, P2, PMP-22, and myelin basic protein in patients with Guillain-Barre syndrome and chronic inflammatory demyelinating polyradiculoneuropathy. | Neurol Neurosurg Psychiatry. 2005;76(10):1431-9.

3. Asbury AK, Arnason BG, Adams RD. The inflammatory lesion in idiopathic polyneuritis: its role in pathogenesis. Medicine (Baltimore).1969;48(3):173-215.

4. Prineas JW. Pathology of the Guillain-Barré syndrome. Ann Neurol. 1981;9(Suppl):6-19.

5. Sun L, He C, Nair L, Yeung J, Egwuagu CE. Interleukin 12 (IL-12) family cytokines: role in immune pathogenesis and treatment of CNS autoimmune disease. Cytokine. 2015;75(2):249-55.

6. Barohn RJ, Kissel JT, Warmolts JR, Mendell JR. Chronic inflammatory demyelinating polyradiculoneuropathy. Clinical characteristics, course, and recommendations for diagnostic criteria. Arch Neurol. 1989;46(8):878-84.

7. Hughes RA, Allen D, Makowska A, Gregson NA. Pathogenesis of chronic inflammatory demyelinating polyradiculoneuropathy. I Peripher Nerv Syst. 2006;11(1):30-46.
8. Köller H, Kieseier BC, Jander S, Hartung HP. Chronic inflammatory demyelinating polyneuropathy. N Engl | Med. 2005;352(13):1343-56.

9. Matsumuro K, Izumo S, Umehara F, Osame M. Chronic inflammatory demyelinating polyneuropathy: histological and immunopathological studies on biopsied sural nerves. J Neurol Sci. 1994;127(2):170-8.

10. Rizzuto N, Morbin M, Cavallaro T, Ferrari S, Fallahi M, Galiazzo Rizzuto S. Focal lesions area feature of chronic inflammatory demyelinating polyneuropathy (CIDP). Acta Neuropathol. 1998;96(6):603-9.

11. Komiyama Y, Nakae S, Matsuki T, Nambu A, Ishigame H, Kakuta S, et al. IL-17 plays an important role in the development of experimental autoimmune encephalomyelitis. J Immunol. 2006;177(1):566-73.

12. Chi LI, Xu WH, Zhang ZW, Huang HT, Zhang LM, Zhou J. Distribution of Th17 cells and Th1 cells in peripheral blood and cerebrospinal fluid in chronic inflammatory demyelinating polyradiculoneuropathy. J Peripher Nerv Syst. 2010;15(4):345-56.

13. Horste GMZ, Cordes S, Pfaff J, Christian Mathys, Anne K Mausberg, Martin Bendszus, et al. Predicting the response to intravenous immunoglobulins in an animal model of chronic neuritis. PLoS One. 2016;11(10):e0164099.

14. Mei FJ, Ishizu T, Murai H, Osoegawa M, Minohara M, Zhang KN, et al. Th1 shift in CIDP versus Th2 shift in vasculitic neuropathy in CSF. I Neurol Sci. 2005;228(1):75-85 
15. Rentzos M, Angeli AV, Rombos A, Kyrozis A, Nikolaou C, Zouvelou V, et al. Proinflammatory cytokines in serum and cerebrospinal fluid of CIDP patients. Neurol Res. 2012;34(9):842-6.

16. Han RK, Cheng YF, Zhou SS, Guo H, He RD, Chi LJ, et al. Increased circulating Th17 cell populations and elevated CSF osteopontin and IL-17 concentrations in patients with Guillain-Barré syndrome. J Clin Immunol. 2014;34(1):94-103.

17. Liang SL, Wang WZ, Huang S, Wang XK, Zhang S, Wu Y. Th17 helper cell and T-cell immunoglobulin and mucin domain 3 involvement in Guillain-Barré syndrome. Immunopharmacol Immunotoxicol. 2012;34(6):1039-46.

18. Lin H, Lee E, Hestir K, Leo C, Huang M, Bosch E, et al. Discovery of a cytokine and its receptor by functional screening of the extracellular proteome. Science. 2008;320(5877):807-11

19. Baghdadi M, Endo H, Tanaka Y, Wada H, Seino KI. Interleukin 34, from pathogenesis to clinical applications. Cytokine. 2017;99:139-47.

20. Van den Bergh PY, Hadden RD, Bouche P, Cornblath DR, Hahn A, Illa I, et al. European Federation of Neurological Societies/Peripheral Nerve Society guideline on management of chronic inflammatory demyelinating polyradiculoneuropathy: report of a joint task force of the European Federation of Neurological Societies and the Peripheral Nerve Society - first revision. Eur | Neurol. 2010;17(3):356-63.
21. Asbury AK, Cornblath DR. Assessment of current diagnostic criteria for Guillain-Barré syndrome. Ann Neurol. 1990;27(Suppl):S21-4.

22. Boulakirba S, Pfeifer A, Mhaidly R, Obba S, Goulard M, Schmitt T, et al. IL-34 and CSF-1 display an equivalent macrophage differentiation ability but a different polarization potential. Sci Rep. 2018;8(1):256.

23. Luo l, Elwood F, Britschgi M, Villeda S, Zhang H, Ding Z, et al. Colony-stimulating factor 1 receptor (CSF1R) signaling in injured neurons facilitates protection and survival. J Exp Med. 2013;210(1):157-72.

24. Mizuno T, Doi Y, Mizoguchi H, Jin S, Noda M, Sonobe Y, Takeuchi H, Suzumura A. Interleukin-34 selectively enhances the neuroprotective effects of microglia to attenuate oligomeric amyloid- $\beta$ neurotoxicity. Am J Pathol. 2011;179(4):2016-27

25. Ma D, Doi Y, Jin S, Li E, Sonobe Y, Takeuchi H, et al. TGF- $\beta$ induced by interleukin-34-stimulated microglia regulates microglial proliferation and attenuates oligomeric amyloid $\beta$ neurotoxicity. Neurosci Lett. 2012;529(1):86-91.

26. Iin W, Dong C. IL-17 cytokines in immunity and inflammation. Emerg Microbes Infect. 2013;2(9):e60.

27. Li S, Yu M, Li H, Zhang H, liang Y. IL-17 and IL-22 in cerebrospinal fluid and plasma are elevated in Guillain-Barré syndrome. Mediators Inflamm. 2012; 2012:260473. 